\title{
Lowering barriers to HCV elimination
}

\section{Sophia Samuel}

If you're still using the drugs, I don't think there's any point. Ifyou're still prepared to stick a needle in your arm, there's no point to get rid of hep $C$, that's the way I see it.

- Research participant completing direct-acting antiviral (DAA) treatment ${ }^{1}$

In 2016, chronic hepatitis C virus (HCV) infection affected approximately 230,000 people in Australia. Treatment was only available in tertiary centres, accessed by fewer than 4000 people per year. This process underwent a substantive change in 2016 when Australia became a global leader by ensuring patients in general practice could receive Pharmaceutical Benefits Scheme-subsided DAAs. ${ }^{2}$

From 2016 to 2020, there was a rapid transition from hospital to communitybased care: 36,000 people received DAAs from more than 6000 general practitioners (GPs), in addition to 46,000 people treated in other specialities. This is all the more remarkable when one considers that $70 \%$ of these GP prescribers treated just one or two patients, and only $10 \%$ treated more than 10 . That is to say: the success of community-based care has been tied to generalist GPs rather than those with a special interest in $\mathrm{HCV} .^{3}$

Muller and Hasan's article discusses removing further barriers to testing and treatment. ${ }^{4}$ Genotyping is recommended, not required, before treatment as DAAs are pan-genomic. A number of patients will not be aware of their infection status. Detection of anti-HCV antibodies indicates exposure to the virus on screening, and $\mathrm{HCV}$ RNA confirms the diagnosis. A quarter of patients will spontaneously clear an acute infection, and repeat testing in six months is required to confirm chronicity. Engagement, assessment for and discussion of treatment with a high chance of cure is a straightforward path for many patients in primary care, including those with ongoing injecting drug use or compensated cirrhosis.

$\mathrm{HCV}$ treatment is an effective illustration of the significant benefits of robust general practice delivering positive health outcomes to patients who were previously excluded. The treating GP does not require additional formal accreditation for their patient to be eligible for DAA treatment, but works within the guidance of an experienced gastroenterologist or infectious disease physician. This facilitates building a professional network and may also offer an example of how, when enough barriers are lowered, general practice manages 'rare' conditions well. In addition, GPs who work in priority settings are often integrated with context-specific and nurse practitioner-led models of care for under-served populations. ${ }^{2}$

High levels of screening and treatment need to be maintained. In-depth, qualitative research in general practice gives voice to the experiences of both GPs and individuals with $\mathrm{HCV}$, identifying challenges to DAA treatment. For instance, recent piloting of finger-prick testing may help address concerns about difficult venous access for blood sampling. ${ }^{1,5}$ Consistent communication can address different perceptions of HCV and DAAs. ${ }^{1,6,7}$ Improving access to fibrosis assessment in primary care, such as transient elastography, not only for HCV infection but also for the more common metabolic associated fatty liver disease, may also facilitate GP engagement. ${ }^{8,9}$

New cases of HCV infection in Australia occur mainly among people who share contaminated needles and syringes while injecting drugs, ${ }^{2}$ and the expectation is that by expanding harm-reduction programs, incidence will fall further. Targeted screening and treatment of other high-prevalence groups in addition to people who inject drugs will shrink prevalence. DAAs will become more effective as 'treatment as prevention' of onward transmission. The World Health Organization has set an ambitious goal of eradicating $\mathrm{HCV}$ as a public health threat by 2030 , and despite the ongoing setbacks of the COVID-19 pandemic, Australia has laid a good foundation to meet this goal. ${ }^{2}$

\section{Author}

Sophia Samuel FRACGP, FARGP; Medical Editor, Australian Journal of General Practice; General Practitioner, Melbourne, Vic

\section{References}

1. Heard W, Smirnov A, Massi L, Selvey LA. How can general practitioners support people who inject drugs to engage with direct-acting antiviral treatment for hepatitis C? A qualitative study. Aust J Gen Pract 2021;50(10):716-21.

2. Department of Health. Fifth national hepatitis $\mathrm{C}$ strategy 2018-2022. Canberra, ACT: DoH, 2018. Available at www1.health.gov.au/internet/main/ publishing.nsf/Content/ohp-bbvs-1/\$File/HepC-Fifth-Nat-Strategy-2018-22.pdf [Accessed 13 September 2021].

3. Stafford F, Dore GJ, Clackett S, et al. Prescribing of direct-acting antiviral therapy by general practitioners for people with hepatitis $C$ in an unrestricted treatment program. Med J Aust 2021. doi: 10.5694/mja2.51204. Epub ahead of print.

4. Muller K, Hasan M. Treating chronic hepatitis C in general practice. Aust J Gen Pract 2021;50(10):697-701.

5. National Hepatitis C Testing Policy Expert Reference Committee. National hepatitis C testing policy 2020. Canberra, ACT: DoH, 2020. Available at http://testingportal.ashm.org.au/files/ National_Hepatitis_C_Testing_Policy_Dec2020.pdf [Accessed 13 September 2021].

6. Parker L, Ryan E, Young S, Hill S. Medications and doctor-patient communication. Aust J Gen Pract 2021;50(10):709-14.

7. Morris L, Selvey L, Williams O, Gilks C, Smirnov A. Reasons for not seeking hepatitis $C$ treatment among people who inject drugs. Subst Use Misuse 2021;56(2):175-84. doi: 10.1080/10826084.2020.1846198.

8. Gofton C, George J. Updates in fatty liver disease: Pathophysiology, diagnosis and management. Aust J Gen Pract 2021;50(10):702-07.

9. Heard E, Massi L, Smirnov A, Selvey LA. Prescribing direct-acting antivirals to treat hepatitis $C$ virus in a general practice setting in Australia: 'So why not do it'? Intern Med J 2020;50:1053-58. doi: 10.1111/imj.14648.

correspondence ajgp@racgp.org.au 